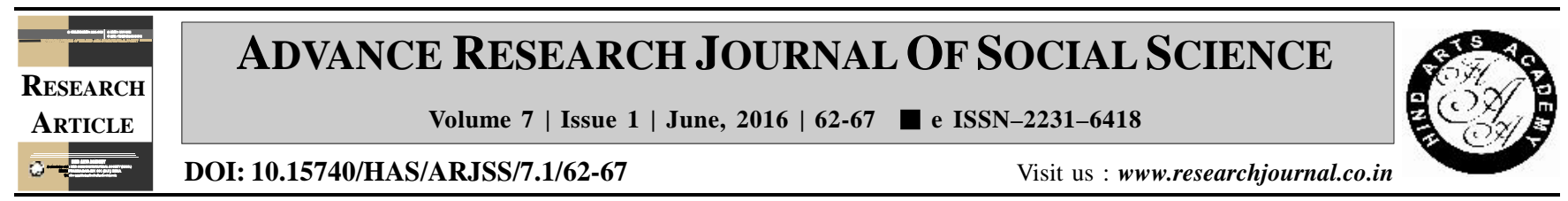

\title{
Information seeking and processing behaviour of KVK's SMS for transfer of technology
}

Prakash Kadam* and Nitin Thoke

Krishi Vigyan Kendra, (Y.C.M. Open University), NASHIK (M.S.) INDIA

(Email:kgpk75@gmail.com)

\section{ARTICLE INFO :}

$\begin{array}{lll}\text { Received } & : & 26.02 .2016 \\ \text { Revised } & : & 08.04 .2016 \\ \text { Accepted } & : & 12.05 .2016\end{array}$

KEY WORDS :

Information seeking, Information processing, Behaviour

HOW TO CITE THIS ARTICLE :

Kadam, Prakash and Thoke, Nitin (2016). Information seeking and processing behaviour of KVK's SMS for transfer of technology . Adv. Res. J. Soc. Sci., 7 (1) : 62-67, DOI: 10.15740/HAS/ARJSS/7.1/ 62-67.

*Author for correspondence

\begin{abstract}
The availability of information sources has drastically increased in all fields in various forms and formats during the last two decades. Information seeking behaviour is an essential component in designing and developing of need based information centers for meeting the information requirements of users. In order to serve agriculture scientists better and design and develop need based information systems and its surrogates. It is an urgent need to focus on the information seeking and processing behaviour of the agriculture scientists covering all facets of their information seeking and processing behaviour. It is necessary to have a clear understanding the various concepts related to information seeking and processing behaviour of agriculture scientists. The study revealed that more than half (57.52 \%) of the Subject Matter Specialists had medium level of information seeking behaviour followed by low level $(23.53 \%)$. Most $(84.31 \%)$ of the respondents 'always' receive information on scientific agriculture by selfobservation method. More than three fourth of the SMS 'always' used group contact sources like discussion with colleagues $(77.12 \%)$ and discussion with farmers (79.13 $\%$ ). About 86.27 per cent and 81.04 per cent of the SMS 'always' used the print media $v i z$., extension publications and newspapers, respectively for information seeking for transfer of technology. Large majority of Subject Matter Specialists evaluated, stored and transformed agricultural information by discussion with fellow scientists and extension personnel, writing in notebooks, and preparation of research report. Majority ( $70.59 \%$ ) of participants exhibited medium level of information processing behaviour followed by 15.69 per cent who had low level of information processing behaviour. More than 90.00 per cent participants stored agricultural information by writing in general notebooks and transformed information by preparation of research report, writing of research/extension articles, folders and radio-talk.
\end{abstract}

